\title{
A Contribuição da Ouvidoria Para a Gestão:
}

estudo de caso no governo do Estado do Ceará.

\author{
Rossana Maria Guerra Ludueña \\ Mestre em Planejamento em Políticas Publicas - UECE
}

\section{Paulo César de Sousa Batista}

Doutor em Economia pela University of Illinois

Professor do Programa de Pós-Graduação em Administração (PPGA) da UECE

\section{Resumo}

O presente trabalho tem como objetivo mostrar a contribuição da ouvidoria para a gestão do Governo do Estado do Ceará, atuando como parceira dentro dos órgãos e entidades do poder executivo, no intuito de prestar um serviço público de qualidade. Para atingir esse objetivo, a autora relaciona aspectos estruturantes das atividades de ouvidoria, com base na legislação federal e estadual específicas do assunto; faz um apanhado de relatos de autores sobre o assunto, inclusive orientações de atuação do instituto pela Ouvidoria Geral da União (OGU); e descreve como ocorre, na prática, a ouvidoria do Governo do Estado do Ceará dentro desses aspectos. As ouvidorias são importantes ferramentas à disposição dos cidadãos e do Estado para facilitar o processo de construção de uma administração que atenda com qualidade aos anseios da sociedade. Metodologicamente, a pesquisa é qualitativa, tendo como estratégia a realização de um estudo de caso da ouvidoria pública estadual, de caráter descritivo. Foram aplicadas as técnicas de pesquisa documental e entrevistas presenciais. As entrevistas foram aplicadas com 12 profissionais do Órgão Central de Ouvidoria do Estado e com uma amostra de 10 ouvidores da Rede de Ouvidoria do Estado. Os resultados revelam um sistema de ouvidoria eficiente para a gestão do Governo do Estado, uma vez que atende aos aspectos investigados, porém não eficaz, em virtude da pouca utilização de suas informações pelos gestores dos órgãos setoriais, de apresentar um índice reduzido de registros de mudanças internas, da não participação da ouvidoria no planejamento do Governo do Estado e o não alcance de suas metas. Contudo, observou-se que ocorreu evolução no processo de capacitação desse serviço, uma vez que a ouvidoria atua dentro de um modelo de gestão em rede, oferece canais de atendimento satisfatórios, possui processo automatizado de atendimento ao usuário, disponibiliza relatórios de gestão de todos os órgãos setoriais do Estado e tem a abertura do Governo para a participação

Palavras-chave: Controle social. Ouvidoria. Gestão pública. 


\begin{abstract}
The objective of this investigation is to evaluate the contribution of the Ombudsman's Office as a tool to support the management of the Government of Ceará, from January 2007 to December 2015, in the provision of quality public service. Methodologically, the research is qualitative, having as strategy the accomplishment of a case study of the State Public Ombudsman, with descriptive and evaluative character. As part of the studies, documentary research and interviews with representatives of the State's central ombudsman's office and a sample of 10 ombudsman's sectoral units were carried out, chosen for concentrating the greatest number of complaints or demonstrations of citizens. The results reveal an ineffective Ombudsman system, due to the low use of its information by the managers of the sectoral organs, to present a reduced index of records of internal changes, the non-participation of the Ombudsman in the planning of the State Government and the lack of scope of your goals. However, it was observed that there was evolution in the process of qualification of this service, since the ombudsman acts within a network management model, offers satisfactory service channels, has an automated process of customer service, provides management reports for all the sectoral organs of the State and has the opening of the Government for popular participation in the control of services as an opportunity to take advantage.
\end{abstract}

Key words: Social control. Ombudsman. Public administration. 


\section{Introdução}

O aprofundamento da democracia no Brasil tem exigido dos órgãos e entidades públicas a adoção de modelos de gestão que ampliem a sua capacidade de atender, com mais eficácia e efetividade, as novas e crescentes demandas da sociedade brasileira.

De acordo com Nassif (2009), ouvidor do governo de Minas Gerais, os grupos sociais vêm pressionando a administração pública a criar mais instrumentos de participação e para controle de seus atos.

Segundo Vieira e Lima (2011, p. 619), os governantes "precisam ouvir atentamente os reclames do povo, as demandas sociais, pois é para esse atendimento que eles foram dotados do poder de governar". Esse autor afirma ainda que este poder não é exclusivo do gestor público, visto que, num processo democrático, toda a sociedade é responsável pela administração pública. Em particular, a Ouvidoria é vista pelo autor como importante ferramenta de estímulo à cidadania e ao controle da sociedade civil sobre as ações públicas.

Esses autores realçam ainda que, com a Constituição de 1988, a "participação do cidadão sai do discurso e torna-se realidade para os movimentos sociais" e esse passa a fazer parte do cenário político, como personagem, importante para a construção da sua realidade.

Vismona (2011) reforça a necessidade de criar instrumentos que modernizem o Estado, estimulando a participação da sociedade na fiscalização dos recursos públicos, no combate ao desperdício e a corrupção, garantindo transparência ao exercício do poder público. Essa prática, chamada de Controle Social, segundo Nassif (2009), deve ser considerada na atual administração pública.

A Ouvidoria apresenta-se como um desses instrumentos, com o propósito de apoiar os gestores públicos na missão de oferecer serviços que atendam às demandas da sociedade e que estejam em consonância com as políticas públicas, além de atuar como instrumento de controle social. Alguns autores defendem a Ouvidoria como parceira do gestor dentro da organização.

Os aspectos estruturantes das atividades de ouvidoria desenvolvidos para o propósito deste foram: a) o perfil e a qualificação do ouvidor, para o trato das informações, retorno ao cidadão com respostas de qualidade das manifestações e articulação com a gestão da instituição em que atua para fazer cumprir os propósitos da ouvidoria; b) Divulgação das atividades de ouvidoria e do resultado de seu trabalho, buscando atingir uma maior cobertura de participação popular e de conhecimento dos canais de atendimento; c) Canais de Atendimento, no intuito de proporcionar maior acessibilidade ao cidadão; d) Processo de Atendimento às manifestações, de forma que atenda aos propósitos da ouvidoria de forma padronizada e célere; e) Governança, e dentro dela, a finalidade e a posição da ouvidoria na estrutura organizacional da instituição em que atua, relacionamento com a alta gestão, participação no planejamento e metas da instituição, e monitoramento e 
avaliação de indicadores e metas de ouvidoria; f) tratamento e destino da informação gerada a partir das manifestações, identificando formas de tratamento e encaminhamento das recomendações e denúncias; e g) Atendimento às recomendações de ouvidoria pelos gestores, evidenciando mudanças internas realizadas pela atuação dos ouvidores.

Metodologicamente, o presente trabalho trata de uma pesquisa qualitativa e descritiva. Foram aplicadas as técnicas de pesquisa documental e entrevistas presenciais. Para a pesquisa documental, foi feito um levantamento bibliográfico em base eletrônica de artigos e nos sítios da Ouvidoria Geral da União (OGU) e da Controladoria Geral da União (CGU), além de outros sítios com abordagem voltada para Controle Social, Gestão Pública e Ouvidoria, com enfoque na Ouvidoria Pública. Foram encontradas poucas publicações a respeito do assunto, porém suficientes para subsidiar a pesquisa, principalmente no que tange a administração pública.

\section{Metodologia da pesquisa}

Quanto à natureza e à abordagem, trata-se de uma pesquisa qualitativa e descritiva. Segundo Gil, as "pesquisas descritivas têm como objetivo primordial a descrição das características de determinada população ou fenômeno ou, então, o estabelecimento de relações entre variáveis" (GIL, 2002, p.42).

Os resultados foram coletados por meio de pesquisa documental, utilizando diretamente o Relatório de Gestão de Ouvidoria de 2015; o Manual do usuário do Sistema de Ouvidoria do Governo do Estado do Ceará (intitulado SOU), dissertações publicadas na internet, conteúdo de sítios institucionais das ouvidorias setoriais do Governo do Ceará; e pesquisa de campo, utilizando entrevistas para colher informações complementares à pesquisa documental, com o auxílio de um questionário com perguntas semiestruturadas, aplicadas de forma presencial, junto a vinte e dois (22) respondentes. As entrevistas foram focadas nos aspectos estruturantes pré-estabelecidos pela autora.

Os dados coletados são referentes ao período de janeiro de 2007 a dezembro de 2015, em virtude da implantação do novo modelo de gestão do poder executivo do Estado, com a publicação da Lei Estadual 13.875 de 07 de fevereiro de 2007 que, na época, vinculou a Ouvidoria-Geral à Secretaria de Controladoria do Estado - SECON.

O universo da pesquisa são os integrantes da Rede de Ouvidoria do Estado, que abrange os ouvidores dos 66 Órgãos/entidades Setoriais do Poder Executivo do Estado do Ceará; e o Órgão Central de Ouvidoria do Estado, representado pela Controladoria e Ouvidoria Geral do Estado (CGE). Do universo de 66 Órgãos e Entidades Setoriais, a autora selecionou uma amostra de 10 órgãos para investigação, por representarem $80 \%$ 
das manifestações da sociedade presencial, via sistema e via e-mail. São eles: Secretaria da Saúde do Estado (Sesa); Secretaria da Educação (Seduc); Secretaria da Fazenda do Estado (Sefaz); Companhia de Água e Esgoto do Ceará (Cagece); Secretaria de Segurança Pública e Defesa Social (SSPDS); Polícia Militar do Estado do Ceará (PMCE); Instituto de Saúde dos Servidores do Estado do Ceará (ISSEC): Secretaria de Planejamento e Gestão (Seplag); Departamento Estadual de Trânsito (Detran) e Polícia Civil do Estado do Ceará (PCCE).

Dentre os respondentes do Órgão Central de Ouvidoria encontram-se: o Secretário titular da pasta, o Secretário Adjunto e o Secretário Executivo, os gestores da Célula de Ouvidoria e da Célula de Acesso à Informação (este último atuando como ouvidor substituto da CGE), o coordenador da coordenadoria de Fomento ao Controle Social - na qual as Células de Ouvidoria e de Acesso à Informação estão inseridas - uma assistente técnica da Célula de Ouvidoria, duas técnicas da equipe de Monitoramento e três (03) técnicas da equipe de Qualidade, ambas também da Célula de Ouvidoria.

A análise dos dados foi feita com recursos à técnica de Análise de Conteúdo. Vergara (2005) afirma ser essa técnica utilizada para tratamento dos dados cujo objetivo é mostrar aprofundadamente tudo sobre determinado tema.

\section{A ouvidoria como instrumento de gestão}

A contribuição da ouvidoria para a gestão pode ser descrita a partir dos seguintes aspectos pré-estabelecidos: Qualificação e perfil do ouvidor, Divulgação e acesso aos canais de comunicação, Governança, Processo de Atendimento às manifestações de ouvidoria, Tratamento e destino da informação gerada a partir das manifestações e Atendimento às recomendações da ouvidoria pelos órgãos/entidades. Para cada aspecto mencionado, são descritos conceitos e relatos de autores (dados teóricos) e a atuação do Sistema de Ouvidoria do Poder Executivo do Estado do Ceará, desde 2007 até 2015 (dados empíricos), mostrando evidências de parceria junto aos dirigentes dos órgãos e entidades do Governo do Estado. A partir desses aspectos pode-se evidenciar a eficiência e a efetividade do instituto de Ouvidoria no Governo do Estado do Ceará.

\subsection{Qualificação e perfil do ouvidor}

Relata Machado, Duarte e Silva (In: Perez, Barreiro, Passone, 2011), que o que faz a ouvidoria atuar como órgão de apoio à gestão da organização e, também, uma ferramenta da democracia, é o fato de "desempenhar um duplo papel: o de atender às necessidades da Organização, ao mesmo tempo em que atende as demandas da sociedade, promo- 
vendo assim, a possibilidade de participação dos cidadãos.

No Governo do Estado, a autora observou os critérios para a escolha do ouvidor nos órgãos e entidades setoriais, se o mesmo se encontra preparado para o cargo, e como acontece a capacitação e desenvolvimento do mesmo para atuar dentro da ouvidoria de um órgão/entidade do Estado do Ceará.

De acordo com o modelo que reza o Decreto Estadual oㅜ 30.938/2012, em Ceará (2012a), o ouvidor do órgão setorial deve ser efetivo e ser designado pelo Dirigente máximo para atuar no órgão/entidade por meio de portaria e responder diretamente ao gestor titular do órgão ou ao gestor de uma área de assessoria da instituição. O perfil exigido para a função de ouvidor, a ser exercida nos órgãos setoriais, consiste no conhecimento sobre a estrutura e política da instituição em que trabalha, sobre governança corporativa, informática, com habilidade de mediação de conflitos e de articulação para tratar com o Órgão Central de Ouvidoria, e que atuem com ética.

Os respondentes do órgão central de ouvidoria e ouvidores foram indagados sobre o critério de escolha do ouvidor utilizado pela instituição em que atua. Segundo o articulador da Coordenadoria de Fomento ao Controle Social da CGE (CFOCS), os dirigentes dos órgãos e entidades da Rede de Ouvidoria são orientados a indicar ouvidor baseando-se no perfil exigido no decreto regulamentado para o fim. A CGE não efetua validação em cima dessa indicação. Segundo o gestor da Célula de Ouvidoria/CGE, existe um acompanhamento dos ouvidores da rede ao longo de suas atividades, desde o momento de sua escolha, sendo apoiado no aprimoramento de sua atuação.

Foi unânime a opinião dos ouvidores entrevistados em afirmar da escolha do ouvidor ser por indicação do dirigente máximo do órgão setorial à CGE. No caso específico da Sesa, que dispõe de uma sub-rede com 55 ouvidorias distribuídas nas unidades assistenciais de saúde, nas Coordenadorias Regionais de Saúde (integrantes da estrutura organizacional da Sesa), nas unidades assistenciais de saúde qualificadas como organização social e nas unidades assistenciais de saúde dos consórcios públicos, a escolha dos ouvidores é feita por processo seletivo pela área de Ouvidoria, indicados pelos gestores das unidades, com etapas de avaliação, entrevista e treinamento.

A autora indagou à equipe do Órgão Central de Ouvidoria sobre o ouvidor estar preparado para o atendimento ao usuário-cidadão, com relação à resposta às manifestações e pró-atividade na resolução de problemas. Considerando a totalidade de 66 ouvidorias até o ano de 2015, 80\% dos respondentes - dentre ouvidores e membros do Órgão Central de Ouvidoria - afirmam que os ouvidores se encontram preparados para assumir a Ouvidoria em suas instituições. Na opinião do Coordenador da área de Fomento ao Controle Social da CGE (CFOCS), as ouvidorias de grande e médio porte - considerando o quantitativo do quadro funcional de efetivos e terceirizados - dedicam-se mais às ativi- 
dades de ouvidoria. Já as de pequeno porte, em que o ouvidor não é exclusivo e acumula atividades de seu cargo, torna-se difícil o desempenho.

A equipe da Coordenadoria de Fomento ao Controle Social da CGE (CFOCS) enumerou algumas ações da CGE voltadas para o desenvolvimento do ouvidor. São elas: cursos preparatórios (para ouvidores iniciantes) e avançados voltados para as atividades de ouvidoria; cursos para elaboração de relatórios de ouvidoria; palestras; reuniões técnicas;

Encontros bimestrais interssetoriais de ouvidores. Foi unânime a afirmação de todos os ouvidores entrevistados de que a CGE apóia o desenvolvimento do ouvidor na capacitação básica e avançada da Ouvidoria, informando sobre o papel e as atividades do ouvidor. Confirmaram a realização de oficinas de qualificação e reuniões bimestrais com a Rede de Ouvidoria; compartilhando informações pertinentes ao Sistema de Ouvidoria; destaques de experiências na área de ouvidoria e ações inovadoras de órgãos setoriais da Rede; e principalmente na orientação das respostas. A Cagece acrescenta que os encontros bimestrais trazem informação, mas não trazem experiências de fora e nem casos de sucesso.

Há a sistemática de capacitar os ouvidores que ingressam na rede de ouvidoria e de serem monitorados ao longo de sua atuação na ouvidoria setorial pelo Órgão Central de Ouvidoria. A deficiência ainda está na escolha do ouvidor.

\subsection{Divulgação e canais de atendimento}

Quase todos os respondentes, dentre ouvidores e Órgão Central de Ouvidoria, admitiram que a divulgação da Ouvidoria para a sociedade não é eficaz. O coordenador da CFOCS/CGE afirmou que a divulgação do instituto ouvidoria e de seus canais de atendimento depende da parceria com a Casa Civil (principalmente a confecção de material como cartazes e folders). Segundo o coordenador, atualmente, a divulgação da ouvidoria do Estado está limitada a Assessoria de Comunicação da CGE, através de redes sociais, matérias em site, releasing; e a palestras realizadas por ouvidores voluntários aos alunos de escolas públicas de ensino médio da capital e do interior, pelo programa de Educação Social, junto à Secretaria da Educação - Seduc. Acrescentou que "[...] falta mais apoio do governo para uma divulgação tanto do serviço quanto dos trabalhos realizados pela ouvidoria”. Governo alega pouco recurso financeiro para o projeto. A divulgação teria maior efeito se as ouvidorias setoriais atuassem mais junto à área de Comunicação de sua Setorial e se a Casa Civil entendesse a ouvidoria como política do governo e não específica da CGE. Mesmo assim, cresce a cada ano as demandas pela ouvidoria, mostrando que mesmo pouca divulgação surte efeito.

Entrevistados da Célula de Ouvidoria mencionaram que desde 2008 a Ouvidoria divulga seus serviços ao cidadão através do Caminhão do Cidadão - unidade móvel da 
Secretaria da Justiça e Cidadania do Estado (Sejus) para emissão de RG e CPF na capital e interiores; e em 2015, junto à Tenda da Cidadania - oferecendo serviços e informações de saúde pública, emissão de documentos e orientação de unidade móvel da Secretaria Especial de Políticas sobre Drogas. A ouvidora da Seduc atribui a responsabilidade de divulgação da Ouvidoria toda ao Órgão Central de ouvidoria à CGE, afirmando que deveria ser mais pró-ativa nesse sentido.

O Gestor da Célula de Ouvidoria/CGE e a ouvidora da Cagece mencionaram sobre o contrato assinado pela CGE para implantar o Sistema Público de Relacionamento com o Cidadão, onde prevê a interligação, por meio de uma única interface, dos atuais Sistemas de Ouvidoria, Acesso à Informação e Transparência do Estado do Ceará, garantindo mais facilidade e agilidade no uso das ferramentas pelo cidadão.

Os Canais de Atendimento do Sistema de Ouvidoria do Estado são compostos pela: a) Central de Atendimento telefônico 155, em que realiza atendimento telefônico feito gratuitamente através do ramal 155 e retornos relacionados à ouvidoria e acesso à informação. Criada em janeiro de 2008 e situada na cidade de Canindé, constitui-se em um dos principais canais receptores e porta de entrada das demandas de ouvidoria de todo o Estado e vem permitindo a universalização dos serviços prestados pela Ouvidoria do Estado do Ceará; b) e-mail: ouvidoria.geral@cge.ce.gov .br; c) Sistema de Ouvidoria (SOU), acessado via Rede Mundial de Computadores (internet); d) atendimento presencial e por correspondência; de modo a viabilizar a recepção e o registro das manifestações tais como: sugestões, elogios, reclamações, críticas, denúncias, solicitações de serviços e informações pertinentes ao Poder Executivo Estadual; e) redes sociais composta pelo microblog Twitter (@OuvidoriaCeara); Facebook/ouvidoriaCeara; e f) o "Reclame Aqui" da Ouvidoria Geral do Ceará. As demandas dos cidadãos que forem recebidas através do Twitter ou Facebook são cadastradas por técnicos da Célula de Ouvidoria da CGE no Sistema de Ouvidoria - SOU, e são encaminhadas para os órgãos e entidades do governo responsáveis pelo assunto em questão. $O$ atendimento presencial pode ser buscado na sede da CGE ou em qualquer órgão ou entidade do Poder Executivo Estadual.

A pouca divulgação das atividades, dos canais de atendimento e dos resultados do trabalho da ouvidoria ainda é um fator limitante para o bom desempenho do instituto. Contudo, os canais de atendimento vêm atendendo as manifestações a contento na visão dos respondentes. 


\subsection{Governança}

Este tópico faz referência à finalidade da ouvidoria nas visões dos autores, do ouvidor e do Órgão Central de Ouvidoria do Governo do Estado; sobre o relacionamento do Ouvidor com a alta gestão e demais gestores da instituição e a aceitabilidade das recomendações da ouvidoria; a influência da posição hierárquica da ouvidoria na autonomia de sua atuação e na obtenção de seus propósitos no órgão/entidade em que atua; também sobre o estímulo dado pelo Órgão Central de Ouvidoria à articulação do ouvidor com outras ouvidorias públicas e privadas; e por último, sobre o Monitoramento e avaliação de indicadores e metas de ouvidoria.

Quanto ao posicionamento da ouvidoria na estrutura organizacional do órgão/entidade, "o posicionamento adequado e satisfatório da ouvidoria, dentro da estrutura organizacional do órgão/entidade é como unidade de assistência direta e imediata ao titular do órgão/entidade, ou estrutura de nível equivalente." (MINISTÉRIO DO PLANEJAMENTO, ORÇAMENTO E GESTÃO, 2013, p. 25).

Segundo a Controladoria-Geral da União (2012), o efetivo funcionamento das ouvidorias depende de sua integração sistêmica. É preciso que se relacionem de forma continuada e em rede, presencial ou virtualmente, "visando compartilhar conhecimentos, aprender e gerar inovações no trabalho das ouvidorias" (CGU, 2012, p.8).

O Secretário e Ouvidor Geral da CGE vê o instituto da ouvidoria como uma ferramenta de controle interno, e como tal, tem a função de auxiliar a gestão, o planejamento e na relação do poder público com o cidadão. Segundo ele, "[...] a ouvidoria dentro do processo de transparência é o instrumento que conversa com o cidadão, diferente dos outros dois que apenas têm a função de informar". Observou que a participação e a transparência fazem parte dos propósitos deste Governo, e que o modelo desenhado em rede e os canais de atendimento para a ouvidoria propiciam essa atuação.

Com relação à posição hierárquica, a estrutura da ouvidoria pública do Estado do Ceará é fortalecida pelo fato de se encontrar na Governadoria (como assessoria direta do Governador). É administrada pelo órgão da Controladoria e Ouvidoria Geral do Estado - CGE, por meio da Célula de Ouvidoria, subordinada à Coordenadoria de Fomento ao Controle Social, acompanhada das Células de Transparência e Ética, a Célula de Acesso à Informação e a Central de Atendimento 155. Fazendo parte das atividades de controle da administração pública, de acordo com a Emenda Constitucional №75, de 20/12/ 2012 (Ceará, 2012b), as atividades do Sistema de Ouvidoria do Poder Executivo do Estado são realizadas pelo Órgão Central de Ouvidoria, através das equipes de Monitoramento e Qualidade da Célula de Ouvidoria/CGE; pela Rede de Ouvidorias; e pela Central de Atendimento telefônico 155. A equipe de monitoramento é responsável pelo monitoramento dos prazos 
de respostas das manifestações e redirecionamento de manifestações/denúncias para ouvidorias setoriais, enquanto a equipe de Qualidade é responsável pela análise e validação das respostas às manifestações dos ouvidores para os usuários/cidadãos.

A Rede de Ouvidorias do Estado é composta por 66 Ouvidorias Setoriais, distribuídas em cada órgão ou entidade do Governo do Estado, exercendo a função de intermediadora dos cidadãos junto às instituições em que atuam, viabilizando um canal de comunicação. Além disso, dispõe ainda da rede interna regulamentada da Secretaria da Saúde - Sesa com 55 ouvidorias distribuídas nas unidades assistenciais de saúde, nas Coordenadorias Regionais de Saúde (integrantes da estrutura organizacional da Sesa), nas unidades assistenciais de saúde qualificadas como organização social e nas unidades assistenciais de saúde dos consórcios públicos.

A CGE orienta que as ouvidorias setoriais estejam localizadas em nível de assessoria do dirigente máximo. De fato, foi observado que a maioria das ouvidorias da amostra se encontra como assessoria direta, seja do dirigente máximo, ou adjunto, ou secretário executivo. Essa posição facilita muito o diálogo com o dirigente máximo da instituição. Mas alguns órgãos setoriais como Cagece, Detran e Sefaz têm suas ouvidorias ligadas à área de comunicação, e a autora constatou que esse casamento vem trazendo bons resultados.

Quanto à estrutura física e de equipe de trabalho, observou-se que algumas ouvidorias atuam com estrutura aquém da necessária. Essa condição influencia no cumprimento do prazo das respostas das manifestações ao usuário cidadão, além de inviabilizar atendimentos presenciais.

Segundo o coordenador da CFOCS/CGE, a atuação da ouvidoria é recente na questão do aprimoramento da gestão e ainda tem um caminho longo a ser percorrido. Acrescenta que no Brasil, nesse contexto voltado para a gestão, a Ouvidoria na iniciativa privada, teve início na década de 80, e no serviço público, começou a ser criada no final da década de 90. A Ouvidoria no Estado do Ceará foi instituída em maio de 1997 e tentou-se firmar desordenadamente. A partir de 2007, quando passou a fazer parte da Controladoria, começou a criar a estrutura, os canais, as ferramentas de controle e a administrar melhor o receber, o tramitar e o responder. Afirma que a partir de 2013, o governo deu um olhar mais macro para a ouvidoria, trabalhando melhor suas informações; aprimorando o Sistema não somente para atender bem, mas para trabalhar as causas e levar informações para apoiar no planejamento; e traduzindo as manifestações para a melhoria dos processos. Portanto, a ouvidoria do Estado encontra-se em processo de construção.

Quanto ao relacionamento do ouvidor com a alta gestão e demais gestores da instituição e à aceitação das recomendações sugeridas pela ouvidoria, segundo o coordenador da CFOCS, algumas mudanças ocorridas nos órgãos setoriais advindas da próatividade das ouvidorias - relatadas pelos ouvidores nos relatórios de gestão - demonstram o início de aceitação do instituto ouvidoria por parte dos gestores da instituição. Cita-se o exem- 
plo da Sefaz, com o registro de muitas denúncias relacionadas a servidores com atuação indevida na fiscalização e liberação de selo da Sefaz para os garrafões de água mineral. As liberações eram feitas manualmente e estavam beneficiando os empresários. A Ouvidoria da Sefaz, devido às articulações junto ao gestor dessa área, conseguiu que esse processo fosse automatizado, diminuindo a interação humana, além de abrir processo administrativo disciplinar para aqueles servidores.

Apesar de 44 ouvidorias setoriais informarem, no relatório de gestão de 2015, que possuem atuação junto à respectiva gestão, o gestor da Célula de Ouvidoria reconhece que os gestores ainda não internalizaram o propósito da ouvidoria. Na opinião do corpo técnico da Célula de Ouvidoria/CGE, os gestores dos órgãos setoriais têm aceitabilidade diferente. Observam isso nos prazos das respostas e na interação dos ouvidores com a equipe de ouvidoria.

O coordenador da CFOCS acrescenta que já houve mudanças em termos de melhoria da comunicação da Ouvidoria com o cidadão e como política de melhoria na gestão. A CGE tem contribuído para essas mudanças através de palestras de sensibilização com ouvidores, gestores e público interno das ouvidorias setoriais, informando sobre o funcionamento da ouvidoria e oportunidades de ganho com os trabalhos realizados por ela.

Todos os respondentes ouvidores compartilharam da afirmação de que têm abertura junto à gestão máxima para apresentar informações da ouvidoria. A maioria tem acento aos comitês executivos, mas ainda não abraçam a ideia de parceria.

Quanto ao estímulo à articulação do ouvidor com outras ouvidorias públicas e privadas, o Órgão Central de Ouvidoria do Estado estimula as ouvidorias setoriais para exporem suas boas práticas nos encontros bimestrais da rede de ouvidores, propiciando a troca de experiência no ambiente da rede. Ainda nesse evento, a CGE leva informações do que se discutem na Ouvidoria Geral da União (OGU), congressos nacionais e outros.

Quanto à promoção de interação com outras ouvidorias fora da rede, a maioria dos ouvidores afirma ainda não haver essa troca de experiência. Da mesma forma, nos encontros bimestrais de ouvidores, lamentam não ter pauta para manifestação dos próprios ouvidores apresentarem suas desconexões.

Quanto ao monitoramento e avaliação de indicadores e metas de ouvidoria, essa atividade é realizada pela equipe de Controle da Qualidade da CGE. Os indicadores são monitorados trimestralmente e os resultados são publicados no Painel do Controle da Qualidade, localizado no site institucional da CGE.

Foram identificados três indicadores de desempenho para medir a qualidade do serviço da ouvidoria. São eles: a) Índice de manifestações procedentes de ouvidoria respondidas no prazo - onde os dados são extraídos do sistema SOU; b) Índice de satisfação do usuário com o atendimento da ouvidoria - onde os dados são informados pelo usuário ao 
receber a resposta via sistema. A pesquisa não é obrigatória; e c) Índice de atendimento das recomendações de ouvidoria (pelos órgãos setoriais) - onde são acompanhadas as ações feitas pelos órgãos e entidades setoriais em cumprimento às recomendações sugeridas pela CGE. O coordenador da CFOCS afirma que o acompanhamento desses indicadores tem resultado em ações preventivas, buscando a melhoria dos índices.

A aceitabilidade da ouvidoria por parte dos Dirigentes dos Órgãos /Entidades Setoriais em suas instituições encontra-se em processo construtivo, considerando a posição da ouvidoria-geral no organograma do Governo como governadoria, assessorando diretamente o Governador e da atuação sistemática do Órgão Central de Ouvidoria no monitoramento das atividades. Com isso, a Ouvidoria-Geral se mostra com maior força, além de atuar como órgão de atividade de controle da administração pública no Estado, conforme as diretrizes regulamentadas por decreto, junto às áreas de Controle Interno e Auditoria, dentro da CGE.

\subsection{Processo de atendimento às manisfestações de ouvidoria}

Dentre as diretrizes descritas pelo Ministério do Planejamento, Orçamento e Gestão (2013, p.38) para a gestão de ouvidorias no poder executivo federal estão a) o zelo pela celeridade e qualidade das respostas às demandas dos seus usuários; b) Discrição no trato das informações recebidas de seus usuários e sigilo da identidade dos mesmos, quando o interessado solicitar a preservação de sua identidade; c) A atuação coordenada, integrada e horizontal entre as unidades de ouvidoria; d) assegurar a preservação dos aspectos éticos, de privacidade e confidencialidade em todas as etapas de processamento das demandas recebidas de seus usuários.

Atendendo às diretrizes contidas no Decreto no 30.938/2012, em Ceará (2012a), o processo de atendimento inicia quando o cidadão (usuário) envia a manifestação, através dos canais disponibilizados pela Ouvidoria do Estado; ao registrar manifestação na internet, via SOU, usuário recebe e-mail automático do sistema com protocolo e senha para acompanhamento da demanda; se a manifestação for via telefone 155, a central atende, registra e classifica a demanda no sistema SOU; se for enviada por e-mail ao órgão setorial ou feita pessoalmente (presencial), o ouvidor da setorial registra e classifica a manifestação no SOU; se a manifestação for enviada por Redes Sociais, Reclame Aqui ou e-mail institucional, cabe ao Órgão Central de Ouvidoria registrar no SOU. O Sistema SOU se encontra adaptado para receber manifestações anônimas.

De acordo com o Decreto oㅜ 30.474/2011, em Ceará (2011), o prazo para resposta das manifestações de Ouvidoria é de até 15 dias, podendo ser prorrogado por igual período com a anuência do gestor do órgão setorial. A partir do momento em que o sistema gera protocolo e senha, a contagem do prazo se inicia, considerando data e horário. Após 
o registro da manifestação, a mesma é encaminhada diretamente à Ouvidoria do órgão referente à solicitação, exceto as denúncias, que passam por uma pré-análise da equipe de monitoramento da Célula de Ouvidoria da CGE, para depois serem encaminhadas ao destino, obedecendo os casos de denúncias definidos na Portaria no 107/2014, em Ceará (2014). O SOU permite que um órgão compartilhe a mesma demanda com outro órgão, fazendo com que esse órgão contribua também com a resposta. O SOU permite transferir manifestações para os gestores das áreas do órgão/entidade responderem. A resposta então é repassada ao ouvidor para melhoramento e, em seguida, encaminhada a CGE. A mesma resposta passa por uma análise e validação da CGE e, depois de validada, é encaminhada ao cidadão. Caso as respostas não estejam claras ou não atendam às orientações da CGE, são devolvidas às ouvidorias setoriais para que realizem as alterações necessárias. Nos casos de descumprimento do prazo de resposta, a CGE articula com a gestão superior dos órgãos e entidades a prorrogação do prazo, com vistas a garantir o atendimento no prazo estabelecido.

Os prazos das manifestações e a qualidade das respostas fornecidas pelas Ouvidorias Setoriais são acompanhados pela equipe de Monitoramento da Célula de Ouvidoria da CGE. Esses critérios são chamados de Resolubilidade das manifestações, que compreende manifestações respondidas ao usuário no prazo estabelecido e com conteúdo das respostas válido. O conteúdo passa por uma validação pela Equipe de Qualidade da Ouvidoria, antes de ser encaminhado ao usuário-cidadão. A equipe se comunica com os ouvidores da Rede de Ouvidoria para esclarecimentos relacionados às manifestações.

As manifestações de ouvidoria (principalmente as denúncias) muitas vezes são encaminhadas para apreciação da área de auditoria e de controle interno preventivo para adoção de providências.

O processo de atendimento às manifestações atende aos propósitos de ouvidoria. Adotando um modelo de gestão em rede, o Sistema atual de Ouvidoria do Ceará caminha a frente de modelos existentes em outros Estados do país, uma vez que garante a uniformidade de processos e procedimentos, e a vinculação das ouvidorias setoriais à direção superior dos seus respectivos órgãos. O Sistema de Ouvidoria do Estado utiliza ferramenta automatizada contendo o fluxo do processo de atendimento e sendo monitorado pelo Órgão Central de Ouvidoria/CGE, além de atender aos propósitos, no que se refere à celeridade e padronização. 


\subsection{Tratamento e destino da informação gerada a partir das mani- festações}

As ouvidorias setoriais fornecem relatórios semestrais de ouvidoria desde o ano de 2011, com dados e estatísticas a partir das manifestações, atendendo às diretrizes contidas nos Decretos de oㅜ 30.474/2011, em Ceará (2011) e 30.938/2012, em Ceará (2012a). Esses dados são consolidados pelo Órgão Central de Ouvidoria/CGE em relatórios de gestão de ouvidoria (anual) contendo informações sobre: Demandas por meios de entrada; Quantidade de manifestações por grupo e tipo de manifestações; Manifestações Classificadas de Acordo com os eixos dos Programas de Governo, e por temas de programas; Quantidade de manifestações por macrorregiões; Tempo médio de resposta das manifestações; Órgãos mais demandados; Satisfação do usuário; Ações inovadoras feitas pelas setoriais; além de informar como se dá a participação do ouvidor junto ao gestor máximo do órgão/entidade em que atua, em comitês executivos, em decisões e planejamentos ou outra forma de participação na gestão. Também são apresentadas recomendações dadas pelos ouvidores e pela CGE, para serem providenciadas pelos Órgãos/Entidades Setoriais, no intuito de atender as recomendações. Em paralelo a CGE encaminha, para cada Órgão/Entidade, ofício com as mesmas recomendações e solicita resposta dos mesmos sobre ações realizadas. Os resultados dessas ações são informados no relatório do semestre seguinte. Os relatórios semestrais e de gestão consolidados são disponibilizados no site institucional da CGE para consultas.

Com relação às denúncias, de acordo com a Portaria n¹07/2014, em Ceará (2014), a CGE criou um Comitê de Apuração Permanente de Denúncias que se reúne, eventualmente para analisar as denúncias relacionadas aos Dirigentes, ouvidores e serviço público em geral do poder executivo do Estado, colhendo elementos que justifiquem a apuração. $\mathrm{O}$ Comitê emite um relatório de tratamento para cada denúncia. A CGE encaminha relatório sobre denúncia envolvendo serviço público, gestores e ouvidor para o dirigente máximo do órgão setorial, solicitando providências sobre as ações tomadas. O Comitê decide se denúncias sobre serviços públicos são encaminhadas ou não para apuração da área de Auditoria da CGE. Denúncias relativas ao Gestor titular do Órgão são apuradas e uma cópia do relatório é enviada ao Governador do Estado.

De acordo com o Secretário e Ouvidor Geral da CGE, a intenção é dar às recomendações de ouvidoria feitas aos órgãos setoriais, o mesmo tratamento dado às recomendações de Auditoria. Para que isso se concretize a CGE está aprimorando a ferramenta denominada Plano de Ação para Sanar Fragilidades (PASF) para acompanhar as recomendações feitas pela ouvidoria, onde cada órgão deverá apontar um plano de ação para as fragilidades apontadas pela ouvidoria. O Sistema será alimentado por uma área especí- 
fica do Órgão/entidade Setorial. O Secretário afirma que está em processo de negociação com a Secretaria do Planejamento e Gestão (Seplag) para que o PPA receba a influência da base de dados das informações de Ouvidoria.

Os relatórios de gestão de ouvidoria, segundo o gestor da célula da ouvidoria, possuem informações que podem contribuir para o planejamento e processo decisório das instituições do Governo. Porém hoje não é utilizado porque falta integração com o Órgão de Planejamento e de Governadoria do Estado, em aproveitar as informações existentes na ouvidoria para subsidiar o planejamento das políticas públicas e orçamento. Isso ocorre em virtude das visões diferentes dos gestores dos órgãos setoriais. Já a ouvidoria da SSPDS acha que o relatório deveria explorar mais qualitativamente os assuntos, detalhando as causas.

O gestor da célula de ouvidoria citou várias contribuições proporcionadas a partir das informações de ouvidoria evidenciadas nos relatórios de gestão. Como exemplo, citou a informação de insatisfação no atendimento prestado pelo órgão devido à má conduta do servidor; na catalogação das manifestações evidenciou-se a recomendação de humanizar e qualificar o servidor público para o atendimento adequado ao usuário-cidadão; e observou-se também a diferenciação de um serviço público prestado na capital e no interior. Como exemplo, cita inúmeras reclamações evidenciando o serviço de emissão de $\mathrm{CNH}$ mais ágil na capital do que no interior do Estado. Também se referiu ao caso da Secretaria das Cidades que, mostra no relatório a causa de reclamações ao atraso do benefício do governo para o Programa Aluguel Social - quantia dada às famílias em processo de desapropriação - ocasionada por suspensão de recursos para o programa. A ouvidoria contribuiu para a celeridade da solução. Acrescentou que o que se precisa é dar publicidade aos relatórios de ouvidoria ao cidadão. E essa ação se concretizará com a implantação do Sistema de Relacionamento que o governo contratou em 2016, já mencionado anteriormente.

O Secretário e Ouvidor Geral da CGE afirma que o governador menciona sempre em seus discursos a importância dos órgãos de controle e de ouvidoria, e se mostra aberto a ouvir reclamações e críticas ao seu governo. Também presenciou o governador divulgando os canais de ouvidoria do Estado. Relatórios de Gestão são entregues ao governador, mas não existe uma sistemática de tratamento ou aproveitamento do mesmo pelo gabinete. A ouvidora do ISSEC informa não sentir apoio do Governador para as recomendações da ouvidoria, uma vez que espera há alguns anos uma solução, por parte do governador, para o plano de saúde dos servidores.

Diante dos avanços tecnológicos e da pressão da sociedade pelo acesso e celeridade das informações, a administração pública tenta adequar-se a inovação tecnológica. No Governo do Estado do Ceará, foi instituído pelo Decreto n‥ 30.474/2011, conforme Ceará (2011), o Sistema Integrado de Ouvidoria - SOU. Trata-se de uma ferramenta infor- 
matizada desenvolvida para otimizar o atendimento das manifestações dos cidadãos encaminhadas à Ouvidoria, compreendendo o registro, o tratamento e o retorno ao cidadão. Segundo informação disponível no site da CGE, a utilização da ferramenta apresenta as seguintes vantagens: permite dar encaminhamento imediato da manifestação à Ouvidoria do órgão competente; facilita o cadastro dos dados; possui recurso de inclusão de anexos na manifestação; apresenta a localização das ouvidorias setoriais por meio da ferramenta GoogleMaps; possibilita o acompanhamento de todo o andamento da manifestação, além de permitir a complementação de informações na manifestação. No endereço eletrônico www.ouvidoria.ce.gov.br, o cidadão acessa o Sistema de Ouvidoria - SOU para registrar sua manifestação.

Os Ouvidores da Rede de Ouvidoria da Sesa utilizam o Sistema OUVIDOR SUS apenas para visualizar as manifestações, mas registram as respostas e novas manifestações manualmente, através de formulário padrão da Ouvidoria da Sesa. A Sesa criou sistema OUVEWEB para atender especificidades que o SOU não atendia. Nele classificam e tipificam as manifestações. O gestor da Célula de Ouvidoria mencionou que a CGE, consciente de grande quantidade de informação que perde, iniciou algumas frentes: negociação para integrar o Sistema Federal Ouvidor SUS com o Sistema SOU; por iniciativa do Governo do Estado, em dezembro de 2016 foi assinado um protocolo de intenções para criar a Rede Ouvir Ceará, integrando os sistemas de ouvidorias de outros poderes ao SOU; Projeto de reestruturar o Sistema de Ouvidoria atual SOU para integrar as informações e relatórios das Secretarias com suas vinculadas.

A consolidação das informações de Ouvidoria ocorre com êxito nos relatórios de gestão de ouvidoria, porém a utilização dessas informações ainda precisa de um direcionamento em nível de governo. As mudanças internas nas instituições, descritas neste documento, ocasionadas pela atuação da ouvidoria setorial, mostra a missão deste instituto como promissor parceiro na gestão.

\subsection{Atendimento às recomendações da ouvodoria}

Aqui são evidenciadas Mudanças realizadas pelos órgãos setoriais frente ao atendimento das Recomendações e Denúncias Recebidas. Nos Relatórios Gerenciais de Ouvidoria são relatadas recomendações e evidências de mudanças ocorridas a partir das providências tomadas pelos órgãos/entidades Setoriais em cumprimento às recomendações, com o objetivo de aprimorar o serviço público e o planejamento de políticas públicas oferecidas à sociedade.

A exemplo, foi sugerido à Sesa melhorar a articulação entre a gestão de pessoas e o processo de agendamento e realização de procedimentos nas unidades assistenciais da 
Sesa. Também de apresentar as necessidades de melhorias na dinâmica interna de trabaIho, com a reestruturação dos fluxos de informações, normas e rotinas, para garantir maior agilidade e eficiência nos serviços. Ações implementadas pela Ouvidoria da Sesa nesse sentido foram: construção de unidades de saúde; na área da gestão, as demandas relacionadas à estrutura e funcionamento foram encaminhadas às áreas administrativas das unidades para aprimoramento e melhoria das instalações das unidades.

$\mathrm{Na}$ Sefaz, foi sugerido implementar o sistema de cupom eletrônico para dinamizar o processamento dos documentos fiscais da Campanha Sua Nota Vale Dinheiro, bem como agilizar o pagamento dos créditos dos participantes. Para isso, foi efetivada a implantação do Sistema de Cupom Eletrônico (DANFE), no ano de 2015, contribuindo para a diminuição na quantidade de manifestações relacionadas ao Programa Sua Nota Vale Dinheiro. As informações da ouvidoria possibilitaram algumas transformações como inclusão de pessoas com melhor perfil e mudanças de gestão e procedimentos, reduzindo o índice de reclamações. Outra área de grande incidência de reclamações foi a de Consultoria Tributária. As informações da ouvidoria possibilitaram algumas transformações como inclusão de pessoas com melhor perfil e mudanças de gestão e procedimentos, reduzindo o índice de reclamações.

Na SSPDS, foi sugerido otimizar e aumentar o policiamento ostensivo com ações estratégicas, investimento no treinamento, e aparelhagem de maior potencial ofensivo; Analisar periodicamente os relatórios do sistema de comunicação da Ciops e das viaturas, a fim de corrigir problemas técnicos; e Capacitar agentes de segurança civis e militares, visando humanizar a atuação junto à população. As providências tomadas pela Ouvidoria da SSPDS foram relacionadas ao aumento do policiamento ostensivo/preventivo; reforço nas ações integradas na área de segurança pública no Ceará com o cumprimento das metas estabelecidas; aumento de abordagens e autuações pelo Batalhão de Policiamento do Meio Ambiente nas ocorrências de poluição sonora; melhoria nos atendimentos da Ciops (tecnológica, pessoal, capacitação, política de segurança) bem como redução na fila de espera, o que impactou na redução do tempo de atendimento das ocorrências; implementações e melhorias nos sistemas tecnológicos de monitoramento e ações de segurança pública; continuidade das ações do Programa em Defesa da Vida em todo o Estado do Ceará por meio de Áreas Integradas de Segurança (AISs); continuidade nas ações de meritocracia para o alcance da meta de redução de crimes; intensificação em ações estratégicas nas grandes operações; Pacto por um Ceará Pacífico apresenta novas diretrizes no combate às drogas e prevenção à violência com a redução no índice de crimes violentos e o programa "Crack, é possível vencer" registra queda de $27 \%$ em mortes violentas nas comunidades atendidas. 
Na Polícia Militar (PMCE), a ouvidora citou: soluções sobre Pensão alimentícia; esclarecimentos ao cidadão sobre como proceder sobre poluição sonora, objeto de grande quantidade de reclamações.

Na Cagece, foi implantado o fluxo de apuração de denúncias como melhoria, para dar mais transparência ao Cidadão. Outra ação para fluir o fluxo de respostas entre as áreas da companhia foi a implantação de facilitadores em cada unidade de negócio. É enviado a cada bimestre Relatório de Gestão de Ouvidoria aos gestores por e-mail, com assuntos mais demandados e estatísticas de tempo de respostas e quantidade de demandas por unidade, no intuito de auxiliar nas atividades internas dos gestores.

No Detran, ouvidor relata sobre a grande quantidade de denúncias concentrada na área de Exames, relacionadas à postura do avaliador na avaliação do candidato no exame prático de direção. A ação da ouvidoria resultou na implantação do serviço de monitoramento, feito por empresa licitada, que consiste na adaptação do veículo com áudio e vídeo, e monitoramento do por profissionais durante a realização do exame, respaldando tanto o candidato quanto o avaliador. Essa ação já se encontra em fase de experiência. Relata casos de demandas reincidentes no interior, cujo atendimento da recomendação foi com demissão de funcionários.

Na Polícia Civil, o ouvidor relata que em virtude de ação da ouvidoria, as soluções muitas vezes ocorrem em articulação direta do ouvidor com os colaboradores e gestores das áreas implicadas, sem ações planejadas, devido o alto dinamismo da instituição. Exemplo de êxito foi uma melhoria no sistema S25 que permite registro instantâneo de ocorrência de roubo de veículo de um boletim de ocorrência feito nos finais de semana nas delegacias de polícia. Antes, a informação do veículo roubado só era registrada na segunda-feira subseqüente, tornando o processo moroso. Outra ação da ouvidoria foi a instalação de totens na instituição para registro de Boletins de Ocorrência, dando agilidade ao processo. Outra ação foi referente à realocação de delegados nas delegacias, em virtude de reclamações dos cidadãos.

No ISSEC, a ouvidora relata situação crítica de problemas relacionados à liberação de exames e que foi com a articulação das informações da ouvidoria junto a empresa autorizadora de exames; outra ação foi a implantação do sistema SISWEB, pela área de Auditoria da instituição, em que através de Cartão Magnético de Saúde do Issec, pacientes do interior teriam prioridade no atendimento.

A ouvidora da Seduc mencionou o caso do Setor de Documentação Escolar - que trata de documentação de escolas extintas - alvo de muitas reclamações do setor se encontrar sempre fechado para atendimento fora do horário estabelecido. Pela articulação da ouvidoria, foi criado um link na página da Seduc para solicitação de documento e o usuário apenas viria ao Setor para recebimento. Além disso, aproveitando a reforma da estrutura física da Seduc, por provocação da ouvidoria, o Setor foi alocado ao lado da ouvidoria e 
com local adequado para atendimento. Ainda sim, o horário foi restabelecido para o atendimento e o responsável pelo mau procedimento foi afastado da unidade.

Observou-se que não existe cobrança de penalidades para os órgãos setoriais no descumprimento às recomendações de ouvidoria. Cabe a cada Órgão/entidade Setorial a apuração de responsabilidade e instauração de sindicâncias. Existe a Corregedoria do Estado, atualmente localizada na Procuradoria Geral do Estado (PGE). Segundo o coordenador da CFOCS, não existe penalidade, e sim a responsabilização do gestor pelo não cumprimento das recomendações do Órgão Central de Ouvidoria. Existem ações de inspeção e fiscalização interna que são iniciadas a partir das manifestações de ouvidoria; e processos de sindicância que originam Processos Administrativos Disciplinares. Processos de correição não são gerenciados pela CGE e, portanto não se toma conhecimento do desfecho. Foram unânimes as respostas dadas pelos ouvidores sobre o desconhecimento de procedimentos a esse respeito.

\section{Considerações Finais}

Apesar do Sistema de Ouvidoria do Estado mostrar-se eficiente em alguns aspectos específicos, a autora observou pontos críticos que dificultam a eficácia da contribuição da ouvidoria como instrumento de gestão do Governo. Um dos pontos principais é a forma como o Governo do Estado se apresenta, estimulando a sociedade a buscar a ouvidoria como canal de diálogo entre o Governo e o cidadão, incentivando o controle social e, no entanto, não vem apoiando financeiramente os projetos e iniciativas do Órgão Central de Ouvidoria. Outro ponto principal é a não utilização das informações de ouvidoria - fornecidas pelos ouvidores dos órgãos setoriais nos relatórios de gestão - pelos gestores dos órgãos setoriais do Estado e pelo gestor máximo da CGE, órgão central de ouvidoria, em seus processos decisórios, de planejamento e na elaboração de políticas públicas para o Estado. Conclui-se, com isso, que os gestores do Estado não reconhecem ainda a ouvidoria como parceira na gestão.

Diante disso, foram apresentadas algumas recomendações no intuito de solucionar as discrepâncias identificadas: com relação ao perfil do ouvidor, sugere-se que a CGE defina melhor o perfil e as competências para o ouvidor, que ela própria realize a escolha dos ouvidores da rede de ouvidoria, sugeridos pelos dirigentes dos órgãos setoriais, que a mesma defina e regulamente padrões de aceitabilidade para atuação do ouvidor, reavalie formas de monitoramento do desempenho do ouvidor ao longo de sua vida funcional, 
não deixando a forma de atuação a seu critério, a fim de garantir que as atividades de ouvidoria sejam feitas por profissional qualificado para a função; Com relação à capacitação, sugere-se uma avaliação por parte do Órgão Central de Ouvidoria sobre a realização dos eventos envolvendo a rede de ouvidores, considerando os aspectos de integração, experiências de outras ouvidorias e, principalmente, espaço para ausculta dos ouvidores da rede; Com relação à divulgação, sugere que o Órgão Central de Ouvidoria elabore um programa de divulgação mais eficaz do serviço de ouvidoria nos municípios do Estado; Com relação à estrutura hierárquica, é preciso que o Órgão Central de Ouvidoria trabalhe tanto para garantir o entendimento pelo dirigente do órgão setorial do papel da ouvidoria como parceira na gestão - uma vez que ela traz informação importante de seus "clientes" para a melhoria dos serviços da instituição - como para dar poder ao ouvidor para exigir o cumprimento de suas recomendações; Com relação à estrutura física para o funcionamento de uma ouvidoria, sugere-se que o Órgão Central de Ouvidoria crie mecanismos para obrigar o gestor do órgão setorial a garantir que a ouvidoria trabalhe com a estrutura básica necessária; Com relação ao atendimento às recomendações de ouvidoria pelos dirigentes, sugere-se que o Órgão Central de Ouvidoria defina estratégia para que os gestores dos órgãos setoriais cumpram as recomendações de ouvidoria, utilizando o sistema Plano de Ação para Sanar Fragilidades - PASF, incluindo etapas de monitoramento e exigência de penalidade para o não cumprimento, uma vez que o Controlador e OuvidorGeral da CGE possui poder de articulação com secretários adjuntos dos outros órgãos - conforme reza o Decreto Estadual no 31.238, de 25/06/2013, e poder para exigir o retorno das recomendações, como lhe confere a Lei № 15.360 de 04/06/2013. O resultado dessas recomendações deve ser divulgado no site institucional da CGE ou no Portal da Transparência.

Por fim, a autora recomenda que o Governo adote estratégia para aproximar tanto as ouvidorias setoriais das áreas de planejamento de seus órgãos/entidades, quanto aproximar o Órgão Central de Ouvidoria dos órgãos estratégicos de planejamento e gestão do Governo do Estado, de forma a participar do processo de planejamento do Estado, apoiada pelos Órgãos Estratégicos do Governo.

Vale ressaltar, que os avanços realizados no período de 2007 a 2015, e aqui relatados, revelam uma ouvidoria em processo evolutivo para se capacitar a oferecer contribuição à gestão do Governo do Estado, uma vez que atua dentro de um modelo de gestão em rede, oferece canais de atendimento satisfatórios, possui processo de atendimento ao usuário automatizado, disponibiliza relatórios de gestão de todos os órgãos setoriais do Estado e oferece abertura do Governo para a participação popular no controle dos serviços. 


\section{Referências Bibliográficas}

BRASIL. Constituição (1998). Constituição da República Federativa do Brasil. Emenda Constitucional n.ำ 19, de junho de 1998, alterando o art. 37. Brasília, DF: Presidência da República, Casa Civil. Disponível em: <http://www.planalto.gov.br/ccivil_03/Constituicao /Emendas/Emc/emc19.htm>. Acesso em 04 jul. 2016.

CARDOSO, Antonio Semeraro Rito; ALCANTARA, Elton Luiz da Costa; LIMA NETO, Fernando Cardoso. Ouvidoria Pública e Governança Democrática. In: Revista do Tribunal de Contas do Estado de Minas Gerais, Belo Horizonte, Edição Especial - ano 2012, p. 27 - 38.

CEARÁ (Estado). Portaria no 107/2014 de 13 de agosto de 2014. Dispõe sobre a instituição da Comissão Permanente de Apuração de Denúncias recebidas Pela controladoria e Ouvidoria geral do estado e dá outras providências. Diário Oficial do Estado do Ceará, Fortaleza, Ce: 21 ago. 2014, série 3, ano VI, nำ154, p.06.

Decreto Estadual no 30.938 de 10 de julho de 2012. Regulamenta o Sistema de Ouvidoria do Poder Executivo Estadual, e dá outras providências. Diário Oficial do Estado do Ceará, Fortaleza, Ce: 12 jul. 2012a, série 3, ano IV, no 132, Caderno único, p.01.

Emenda Constitucional n. 75, de 20 de dezembro de 2012. Altera dispositivos da Constituição Estadual. Diário Oficial do Estado do Ceará. Fortaleza-CE: 27 dez. 2012b, série 3, ano IV, n. 244, p. 214.

Decreto Estadual no 30.474 de 29 de março de 2011. Institui o sistema de ouvidoria - SOU, e dá outras providências. Diário Oficial do Estado do Ceará, Fortaleza, Ce: 30 mar. 2011, série 3, ano III, no 061, p.01.

CGU - Controladoria-Geral da União. Controle Social: orientações aos cidadãos para participação na gestão pública e exercício do controle social. Brasília, DF, 2012. (Coleção Olho Vivo no Dinheiro Público). Acessado em 01/08/2015. 
GIL, Antônio Carlos. Como elaborar projetos de pesquisa. 4.ed. - São Paulo: Atlas, 2002.

LYRA, Rubens Pinto (org.). Ouvidor: o defensor dos direitos na administração pública brasileira. Paraíba, 2004, 30 p.

MACHADO, José De Ambrosis Pinheiro; DUARTE, Silvio; SILVA, Vera Lucia Rodrigues da. A implementação de Ouvidorias públicas e privadas: modelo de gestão por processos. In: PEREZ, José Roberto Rus; BARREIRO, Adriana Eugênia Alvim; PASSONE, Eric (orgs.). Construindo a Ouvidoria no Brasil: Avanços e perspectivas. Campinas SP- Unicamp/ouvidoria, 2011, p. 145-166.

MINISTÉRIO DO PLANEJAMENTO, ORÇAMENTO E GESTÃO. Guia de Orientação para a Gestão de Ouvidorias. Brasília, DF, Ago. 2013.

NASSIF, Gustavo Costa. As Ouvidorias públicas no contexto de um novo modelo de governança. Revista do Tribunal de Contas do Estado de MG. Belo Horizonte, MG, v.73, n.4, Ano XXVII, p. 45-60, Out/Nov/dezembro, 2009.

OGU - Ouvidoria Geral da União - Orientações para implantação de uma unidade de Ouvidoria - rumo ao sistema participativo. 5a edição. Revisada e atualizada. Brasília. DF. 2012. Coleção OGU. Controladoria-Geral da União - CGU.

OLIVEIRA, João Elias. Ouvidoria pública brasileira: evolução de um modelo único. In: Vismona, Edson. A Ouvidoria brasileira (org.) p. 45-54. São Paulo: Associação Brasileira de Ouvidores/Imprensa Oficial do Estado de São Paulo. São Paulo, 2005.186p. Disponível em: http://www.abonacional.org.br/artigo.php?codigo=28

PINTO, Eliana. A Ouvidoria como instrumento de controle social. Revista TCMRJ do Tribunal de Contas do Município do Rio de Janeiro. Ano XXVIII. n. 46, p. 31-36, janeiro.2011. Disponível em: www.ri.gov.br. 
VERGARA, Sylvia Constant. Métodos de Pesquisa em Administração. São Paulo: editora Atlas, 2005.

VIEIRA, Evaneide Dutra; LIMA, Hermano Machado Ferreira. Cidadania e Controle Social: a Ouvidoria como instrumento de controle e participação na administração pública. Revista do Mestrado Profissional em Planejamento em Políticas Públicas, Fortaleza, Ce, p. 616638, mai/ago. 2011.

VISMONA, Edson Luiz. A Evolução das Ouvidorias no Brasil. In: PEREZ, José Roberto Ruz; BARREIRO, Adriana Eugênia Alvim; PASSONE, Eric. (Orgs.). Construindo a Ouvidoria no Brasil: avanços e perspectivas. Campinas: UNICAMP/Ouvidoria, 2011, p. 29-42. 